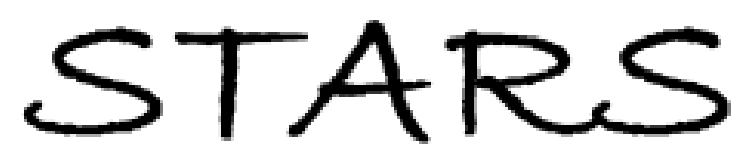

University of Central Florida

STARS

$4-5-2014$

\title{
Are there gender differences in what drives customer delight?
}

\author{
Edwin Torres \\ University of Central Florida, edwin.torres@ucf.edu \\ Xiaoxiao Fu \\ Xinran Lehto
}

Part of the Hospitality Administration and Management Commons, and the Tourism and Travel

\section{Commons}

Find similar works at: https://stars.library.ucf.edu/rosenscholar

University of Central Florida Libraries http://library.ucf.edu

This Paper is brought to you for free and open access by the Rosen College of Hospitality Management at STARS. It has been accepted for inclusion in Rosen Faculty Scholarship and Creative Works by an authorized administrator of STARS. For more information, please contact STARS@ucf.edu.

\section{Original Citation}

Torres, E., Fu, X., \& Lehto, X. (2014). Are there gender differences in what drives customer delight? Tourism Review, 69(4), 297-309.

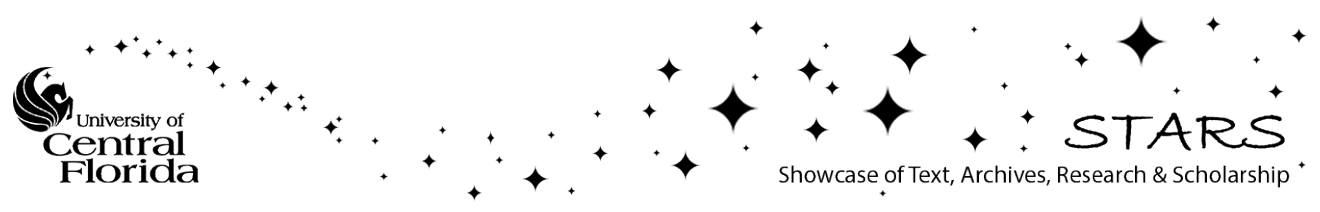




\title{
What Drives Customer Delight: Exploring gender differences in the delight experience
}

\begin{abstract}
Purpose - The present research sought to understand how male and female guests become delighted customers. The similarities and differences are presented along with respective implications for theory and practice.
\end{abstract}

Design/methodology/approach - Tourists were interviewed in an upscale Florida hotel for a period of three months. A total of 208 semi-structured interviews were conducted. The script for the interviews was based on an interview protocol used by Crotts et al. (2008). Adapted from a previous customer delight study (Torres \& Kline, 2013), a codebook was developed to ascertain the salient themes that emerged during the interviews. Interviews were coded independently by three experienced reviewers using the process of content analysis.

Findings - The results demonstrated, while men and women agreed on most aspects of the service experiences that led them to feel delighted, there were other aspects of the delight experience that seemed to vary by gender. More specifically, female guests were more likely to be delighted by employee friendliness and professionalism. In contrast, male tourists appeared to be more likely to be delighted by having their needs met efficiency and timeliness of service, and availability of complimentary amenities or upgrades.

Research and Practical Implications - This study contributes to the existing literature by demonstrating that men and women can potentially be delighted by different aspects of the service experience. Such information may well benefit hospitality industry practitioners to deliver service experiences desired by each gender.

Originality/value - Eckinci et al. (2008) proposed that the ultimate evaluation of customer experiences can be highly individualized with elements such as personality. The present research 
argues that the process of delighting customers might be more complex than originally conceived. Accordingly the results suggests: a) a universal set of criteria will tend to delight all guests, and b) a more specific set of criteria will potentially delight guests of a certain gender. Future research is encouraged to quantitatively validate the findings, as well as explore other factors that impact customer delight such as personality, age, income, and culture.

Keywords: Customer delight, Customer satisfaction, gender differences, hotels

\section{Introduction}

One of the primary goals of a service provider is to deliver an experience that is truly memorable for every guest. Given this need, practitioners and scholars have turned their attention to the topics of customer satisfaction and loyalty. Despite all the emphasis placed on customer satisfaction, many hospitality businesses still struggle to maintain loyal customers in a competitive environment. In fact, the link between the level of satisfaction reported by a customer and the extent of loyalty he or she actually demonstrates has been questioned, as empirical evidence suggested that merely satisfied customers are not necessarily loyal nor committed (e.g. Skogland \& Siguaw, 2004). While customer satisfaction has been the staple of measuring customer engagement for decades, the relatively newer concept of customer delight has been proposed as a potential alternative in addressing customer relationship management. It was posited that delighting customers, rather than merely satisfying them, may point to a better strategic direction.

It has been demonstrated in many customer studies that as the level of satisfaction increases, customer loyalty increases as a result, which in turn contributes to the overall corporate performance. In fact, Patterson (1997) indicated that companies with loyal customers can 
succeed with prices $7 \%$ higher than their competitors. In light of this, it may not be surprising to note that more than satisfied customers were more likely to be loyal and lucrative than customers who were just satisfied (Kumar, et.al., 2001; Rust \& Oliver, 2000). As a stage beyond satisfaction, customer delight has also been suggested to have a stronger impact on affective loyalty when compared to customer satisfaction (Finn, 2005; Kim, 2011). As a consumptionrelated concept, the arousal of customer delight can be highly individualized as it is possible for different customers to be delighted by different drivers (Ekinci et al., 2008). However, customer delight experience has not been delineated to examine if any variance exists among customers of different backgrounds. As a pioneering effort, the present research explores the relevance of gender as a demographic trait to the experience of customer delight.

\section{Theory}

\subsection{Customer Delight Defined}

Researchers have attempted to define the concept of customer delight. In doing so, they have approached it from one of three perspectives: attitudinal, affective, and needs-based. Stressing the disconfirmation paradigm, Patterson (1997) proposed that customer delight is where the experience goes beyond satisfaction and a pleasurable experience is incurred on the guest's side. According to Keinningham et al. (1999), customers have a certain zone of tolerance. Performing beyond the upper thresholds of such zone would generate customer delight. Within the realm of affect-based definitions, Kumar, Olshavsky, and King (2001) proposed that customer delight is composed of the emotions of joy, thrill, and exhilaration. Finn (2005) defined customer delight as an emotional response which results from surprising and positive levels of performance. 
Finally, Schneider and Bowen (1999) suggested that customer delight is a function of the satisfaction of three human needs: security, justice, and self-esteem.

Admittedly, delight and satisfaction share some common characteristics. According to the expectancy-disconfirmation model (Oliver, 1980), customers are expected to compare prepurchase expectation with the actual experience of product or service. If perceived performance fails expectation, dissatisfaction or outrage will occur. If perceived service quality exceeds expectation, then positive responses such as satisfaction or delight will arouse. Therefore, delight and satisfaction are unified by their common nature as positive emotions. However, delight goes beyond satisfaction. Compared to satisfaction, delight stresses the state of emotional attachment and is more strongly associated with customer loyalty, positive word of mouth, and repeat purchase intent (Torres \& Kline, 2006). On a continuum Berman (2005) proposed four stages to measure post-purchase customer responses. Specifically, they are outrage/pain, dissatisfaction, satisfaction, and delight. As customer emotions moves through the continuum from negative to positive, customer loyalty is expected to ascend.

One source of controversy within in customer delight research is the element of surprise. Whereas some researchers believe that surprise is an integral part of the delight experience, as it triggers a disconfirmation on the positive side; other researchers believe that guests do not need to be surprised in order to be delighted. For example, researchers have proposed that the emotional state of being delightful is a blend of happiness and surprise (Kumar et al., 2001; Berman, 2005). This is in keeping with Oliver et al. (1997) proposition that surprise acts as an antecedent for delight to occur. Research by Crotts and Magnini (2010) examined online customer reviews on Trip Advisor and uncovered that the surprise component was strongly associated with customer loyalty (Crotts \& Magnini, 2010). Surprise may also trigger emotional 
arousal, which has been proven to have a major effect on customer delight (Bowden \& Dagger, 2011).

\subsection{What delights the guest?}

Scholars and practitioners are in constant search for the elements that delight their guest, in order to find ways to better replicate such experiences. It could be argued that some of these factors are situation-specific, whereas others might be more universal in nature. These factors can be critical, as they affect a guest's evaluation and likelihood of repeat purchases and positive word of mouth communication. Despite the relevance of delight drivers to understanding customer experience, very few studies have actually dedicated to empirically dissect what delights customer in a hotel environment.

Among the limited empirical studies, Crotts et al. (2008) investigated key delight drivers in the context of a food and wine festival, where "diversity of wines and food tasting" and "quality of the food samples" were identified as two major factors that contribute to participants' delight. Also noteworthy is that, although respondents mentioned negative impressions of the festival such as "lack of seating" and "too crowded", they still rated the overall experience as positive and demonstrated strong revisit intention. Through content analysis of the written feedback letters from 105 guests, Torres and Kline (2013) postulated a typology of customer delight. Five major conceptual themes were presented, including charismatic delight (associated with employee friendliness personality), fulfillment delight (associated with the fulfillment of higher-level needs such as that of self-esteem), problem resolution delight (resulting from the effective solution of a guest problem, especially when it was not the hotel's responsibility), professional delight (resulting from employee professionalism), and comparative delight 
(emerging from the realization that a hotel is superior to that of competitors). The customer delight typology is important in that: a) it establishes the possibility that guests can be delighted in different ways, and b) the culture of the organization can influence the way in which delight is attained.

Despite the existing knowledge on the conceptual nature of customer delight, it has not been dissected to determine if there is any gender-based difference, although abundant empirical evidence has suggested that men and women may differ in their evaluations of product and service consumptions (Oh, Parks, \& Demicco, 2002). More specifically, customers' information processing strategies in a service environment seem to demonstrate gendered variance (Dube \& Morgan, 1996; Meyers-Levy \& Maheswaran, 1991; Meyers-Levy, 1991). Through three experiments, Iacobucci and Ostrom (1993) provided support that women may be more sensitive to relational aspects of a service encounter than men who seemed to be more receptive to the core aspects. However, whether or not gender differences extend to perceptions of a delightful experience in lodging environment has not been empirically assessed. It remains unclear which factors would be more influential to male or female customers in deriving a delightful consumptive experience.

\subsection{Study Objectives}

When examining the various streams of literature on customer service, it is apparent that service failure and service recovery has received a fair deal of attention. Nevertheless, far less emphasis has been given on positive service experiences. Emphasizing both aspects of emotional attachment and peak experience, the concept of customer delight has accordingly become a topic of interest (Keinningham, et al., 1999; Kumar, et al., 2001; Finn, 2005; Torres \& Kline, 2006). Despite its strategic relevance to service experience, little is known about how customer delight 
may be experienced differently across different demographic characteristics. Therefore, the present study proposes a qualitative study in an attempt to delineate potential similarities and differences in the delight experience of male and female guests. Specifically, the current research aims to address the following questions:

- Is customer delight experienced differently by men and women?

- What are some common drivers of customer delight (if any) that are universal across both genders?

- What are some drivers of customer delight that are gender-specific?

\section{Methodology}

The present research utilized semi-structure interviews to gain rich information about a guest's delightful hotel experience. During the course of the study, an interview protocol was developed based on the instrument introduced by Crotts, et al. (2008). Some of the questions proposed by Crotts et al. (2008) include: a) What are three things you enjoyed most about your visit?; b) What are the three things you enjoyed least about your visit? C) I thoroughly enjoyed my visit (on a scale from "strongly disagree" to "strongly agree") among others. In addition to these questions, the researchers also asked questions regarding some of the customer delight drivers identified in the typology proposed by Torres and Kline (2013), namely friendliness, professionalism, fulfillment of esteem needs, and problem resolution.

The present research sought to obtain descriptions of factors that contribute to a delightful experience. The researcher's intent was not to give a sweeping generalization of the difference between guests of different cultures, but to provide insights into the phenomenon under investigation. The interviews were conducted in an upscale hotel in the Central Florida area during a period starting on January 2013 and ending on March 2013. A total of 208 
interviews were conducted during this period (for more results on respondent demographics, please see the results section). Prior to the interviews the researchers obtained permission from the hotel's management as well as the university Internal Review Board (IRB). Hotel guests both male and females were approached for qualitative interviews in various public spaces of the hotel.

With permission of the guests, the interviews were recorded in written notes and thereafter transcribed. The interview transcripts were coded independently by three trained coders. All raters had expertise in the area of customer delight. A codebook was developed and interviews transcripts were subsequently coded using a process of content analysis. According to Iverson (2000), content analysis has several advantages. "First, it helps researchers analyze people's account of an event without taking away its power or eloquence. Content analysis consists of multiple steps, beginning with the development of categories, followed by coding of the material and ending with the statistical analysis of data. This method is suitable for increasing knowledge of subjects that have received little previous attention" (Iverson, 2000). The interview transcripts were evaluated for the presence of each code and frequency counts were obtained.

The analysis followed both an inductive and a deductive process. The codebook was initially developed based on the review of related literature. Torres and Kline (2013) in their research developed a codebook for content analysis. This study used a modified version of such codebook. Additionally, as the coders read the letters; new themes emerged. Consequently, the codebook was modified to contain all of the relevant themes from the letters of feedback, as well as the information from the relevant literature. In light of this, the process both utilized information from the literature and also utilized the transcripts themselves to draw additional 
themes and patterns. Following the independent coding of all three raters, an assessment of reliability took place. During the initial round of coding, a level of agreement of $82 \%$ was obtained. After this, the raters met and discussed the coding of the interview transcripts, reaching final coding decisions. During the final round of coding, a level of agreement of $90.1 \%$ was obtained. Kappa value was calculated as a means of inter-rater reliability. A kappa value of .727 was obtained among the raters. Therefore, a substantial level of agreements and kappa value were obtained.

\section{Results}

Following the coding of the customer letters, the researchers added the frequency and percentage occurrence of each code for each gender. Male respondents totaled 121 or $58 \%$ of all the interviewees. Some of the most frequently mentioned service attributes included: friendliness (55\%), satisfaction of higher level needs (44\%), and service that is accommodating and flexible (44\%). The division of the department that was most likely mentioned in their delight experience was housekeeping/cleanliness $(22 \%)$ followed by the front office $(18 \%)$. In terms of men's amenity choices, a strong preference was received for complementary items and upgrades (21\%).Women respondents totaled 87 or $42 \%$ of all respondents. Some of the most frequently mentioned service attributes included: friendliness (64\%), professionalism (55\%), service that is accommodating and flexible (49\%), and problem resolution (29\%). The division of the department that was most likely mentioned in their delight experience was housekeeping / cleanliness $(23 \%)$ followed by the front office $(18 \%)$.

Given the frequencies for both males and females, some differences were apparent based on the content analysis of the interviews. First, men have a stronger preference for complementary 
amenities, services, and upgrades (21\%) as opposed to females (7\%). Although friendliness in service was universally delightful, it appeared in higher frequency in women's interviews (64\%), as opposed to men (55\%). Women also placed greater emphasis on other intangible service items such as professionalism (54\%) when compared to men (44\%). Men had a higher recollection of delightful experiences where their esteem needs were satisfied (44\%) as opposed to women (30\%). Finally, men valued efficiency and timeliness (26\%) more so than women (18\%). For a detailed comparison of male versus female customer delight frequencies, see Table 1.

Despite the differences between men and women, there were some universal components to the delight experience. Service that is accommodating and flexible can be equally delightful to males and females. Some attributes of the hotel ambiance can also play a role in delighting both men and women. More specifically, the room and overall facilities and location were similar in terms of the frequencies of customer delight. Both genders seemed to place similar importance to most service departments including front office, guest services and housekeeping. 
Table 1: Men and Women Customer Delight Comparison

\begin{tabular}{|c|c|c|}
\hline Code & Women & Men \\
\hline 1- Room & $29 \%$ & $28 \%$ \\
\hline 2- Lobby & $0 \%$ & $1 \%$ \\
\hline 3- Pool \& Leisure facilities & $14 \%$ & $10 \%$ \\
\hline 4- Facilities - gym, and other public spaces & $3 \%$ & $2 \%$ \\
\hline 5- Overall superior facilities and location & $21 \%$ & $17 \%$ \\
\hline 6- Surprise & $6 \%$ & $9 \%$ \\
\hline 7- Friendliness & $64 \%$ & $55 \%$ \\
\hline 8- Problem Resolution & $29 \%$ & $29 \%$ \\
\hline 9- Professionalism & $54 \%$ & $42 \%$ \\
\hline 10- Needs satisfied (i.e. self esteem) & $30 \%$ & $44 \%$ \\
\hline 11- Accommodating / Flexible & $49 \%$ & $45 \%$ \\
\hline 12-Personalized Service & $13 \%$ & $18 \%$ \\
\hline 13-Efficiency / Timeliness & $18 \%$ & $26 \%$ \\
\hline 14- Front Office & $18 \%$ & $19 \%$ \\
\hline 15- Housekeeping & $23 \%$ & $22 \%$ \\
\hline 16- Room service - culinary & $2 \%$ & $5 \%$ \\
\hline 17- Room service - service & $1 \%$ & $7 \%$ \\
\hline 18- Restaurant \& Lounges - culinary & $15 \%$ & $9 \%$ \\
\hline 19- Restaurants \& lounges - service & $10 \%$ & $15 \%$ \\
\hline $\begin{array}{l}\text { 20- Guest services (i.e. concierge, bell staff, } \\
\text { etc) }\end{array}$ & $10 \%$ & $12 \%$ \\
\hline 21- Banquets & $0 \%$ & $1 \%$ \\
\hline 22-Amenities - others & $13 \%$ & $14 \%$ \\
\hline $\begin{array}{l}\text { 23- Complimentary amenities / services / } \\
\text { upgrades }\end{array}$ & $7 \%$ & $21 \%$ \\
\hline
\end{tabular}

$\mathrm{N}($ total $)=208 ; \mathrm{n}($ men $)=121 ; \mathrm{n}($ women $)=87$ 


\section{Discussion}

\subsection{Theoretical Contributions}

Men and women share many of the same experiences of being delighted. Indeed, the common human experience and the pursuit of universal service values such as friendliness and fair treatment are important to both genders. Upon closer examination of the 208 delight experiences of a sample of men and women, some differences emerged. Men's preference for complementary amenities, services, upgrades, as well as the emphasis on the satisfaction of esteem needs, points out to a style of service that is highly individualized. Furthermore, it seems that men are motivated to fulfill their higher level of individual needs during their service experience and an emphasis on the concept of value was far more prevalent in men than women. In contrast to men, women demonstrated a greater preference for some of the intangible aspects of the service experience. Such are more related to the overall care and concern for the hotel guests, as opposed to the provision of their individual needs whether physiological or

psychological. Women stressed professionalism and friendliness in more so than men. Therefore, it can be inferred that most women prefer a style of service which is friendly, but at the same time not overly friendly, personalized, but not overly personal.

A key contribution of this paper is that some customer delight drivers such as friendliness, problem resolution, and flexibility are universal in nature. This is consistent with the framework proposed by Torres and Kline (2013). Other aspects such as the satisfaction of esteem needs, timeliness and efficiency, professionalism, and the provision of complimentary amenities and upgrades seem to have different effects depending on the gender. Previous research suggested that men and women differed in terms of their evaluation of product and service consumption (Oh, Parks, \& Demicco, 2002). The present study contributes to the field of knowledge by 
suggesting that the feeling of delight can be bought about by different drivers depending on the demographic traits of the individual, in this case, gender.

\subsection{Practical Implications}

Service providers face many difficult decisions about how to best shape the service experience to delight guests. An important consideration of such a process is the provision of services and amenities that will delight all guests in general, versus those that will be proffered by a certain demographic. As marketers attempt to appeal to various consumer segments, and hoteliers attempt to delight their guests, it's critical to understand what delights the guests. Previous research has studied the concept of customer delight (Berman, 2005; Crotts \& Magnini, 2010; Finn, 2005; Keinningham, et al., 1999; Kumar, et al., 2001; Schneider \& Bowen, 1999, Torres \& Kline, 2013), yet little evidence exists about how the process can be different for various groups of individuals. The present research explored the differences specifically exploring gender differences. Future research can explore other individual differences such as age and culture in order to ascertain their impact in customer delight.

Hoteliers can always delight their customers by addressing the universal dimensions that lead to customer delight, which have been explored in the previous literature. However, based on this research a few implications emerge. First, in order to provide a more delightful hotel experience for men, service providers ought to look closely at the personalization of service, as well as the satisfaction of esteem needs. Making men feel welcome, comfortable, and special can go a long way towards delighting them. This may imply actions such as providing guests with complements, asking about their comfort, and acknowledging their status. Complimentary amenities and upgrades no matter how small can also drive the point of making guests feel 
special, especially in the case of men. When it comes to delighting women, hoteliers must ensure that they are treated in a friendly, yet professional manner. Women seemed to appreciate the flexibility in service. In contrast, men seemed to appreciate the efficiency aspect more than women. Training the hotel's staff to be flexible and accommodate specific requests can help attract and retain female guests.

While hoteliers can spend a substantial amount of time, effort, and treasure in providing certain tangible items and services, it is the intangibles of service that are most likely to delight the guests. Granted rooms, facilities, and other aspects are not only important, but also mentioned by guests during this interview process; what really pushes a hotel from good to great is the service it provides its guests. Service that is highly personalized and conscious of guests needs is likely to delight men, while service that is friendly, yet professional is likely to have a greater impact in women.

\subsection{Conclusions, Limitations, and Future Research}

While the present study provides great insight as to the various elements that comprise customer delight from a gender perspective; it is also noteworthy to state that some limitations exist. During the course of the study interviews were utilized. While the researchers conducted a significant number of interviews, future research can explore this topic from a quantitative perspective. This study focused on one sector of the tourism industry: hotels. Future research can study customer delight in other settings such as theme parks, events, and foodservice. In order to expand the scholarly work on customer delight, future research can explore other individual differences such as age, and culture. 
In the objectives section, the researchers posed three research questions. The answers to these questions are presented as follows:

- Is customer delight experienced differently by men and women?

Customer delight is a feeling that can be experienced by both men and women. While the literature points out to similar conceptualizations and consequences; the drivers of customer delight can be different based on the gender.

- What are some common drivers of customer delight (if any) that are universal across both genders?

Some customer delight drivers such as friendliness, problem resolution, and flexibility are universal in nature. Additionally, men and women seemed to agree with regards to the impact of various tangibles (i.e. room, and overall facilities) and their influence on their feelings of delight. For both men and women, the service departments more closely associated with their delight experience were housekeeping and the front office. Therefore, it can be stated that several drivers of customer delight are universal in nature, while some can be gender-specific.

- What are some drivers of customer delight that are gender-specific?

Overall men show a preference towards the satisfaction of individual needs. In this study, they expressed delight with the satisfaction of their esteem needs, as well as the provision of complimentary amenities and upgrades. In contrast, women expressed more delightful experiences associated with friendliness, and professionalism than men. The delight drivers for men are those that propose a superior value proposition, and satisfy their individual needs. The delight drivers for women seem to be those intangible aspects of the service experience that provide a superior service to all guests. 
Delighting all guests is a worthwhile pursuit. However, gaining a better understanding of what delights guests is a constant undertaking of both scholars and practitioners. The present study demonstrated that some aspects of delight are universal to the human experience, while others are gender-specific. Therefore, service providers seeking to appeal to men or women can take advantage of this information to enhance their service experience. The delight experience can be more individualized than initially conceived. Therefore, future research can explore the effect of other individual differences on customer delight. As service providers seek to transform their service experience by moving from satisfaction to delight, it is important to know that men and women can be delighted by different aspects service. Learning from the evidence of the present research and that which has been proposed by the existing literature, scholars and practitioners can drive specific aspects of their service strategy, in order to make a service experience that is truly memorable. 


\section{References}

Berman, B.(2005), "How to delight customers", California Management Review, Vol. 48 No. 1, pp. 1129-151.

Bowden, J., \& Dagger, T. (2011), “To delight or not to delight?” An investigation of loyalty formation in the restaurant industry", Journal of Hospitality Marketing \& Management, Vol. 20, No. 5, pp. 501-524.

Crotts, J., Pan, B., \& Raschind, A. (2008). “A survey method for identifying key drivers of guest delight”, International Journal of Contemporary Hospitality Management, Vol. 20 No. 4, pp. 462-470.

Crotts, J, \& Magnini, V. (2010). “The customer delight construct: Is surprise essential?”, Annals of Tourism Research, Vol. 37 No. 4.

Dube, L., \& Morgan, M. (1998), “Capturing the dynamics of in-process consumption emotions and satisfaction in extended service transactions", International Journal of Research in Marketing, Vol. 15 No. 4, pp. 309-320.

Ekini, Y, Dawes, P., \& Massey G. (2008). “An extended model of the antecedents and consequences of consumer satisfaction for hospitality and services", European Journal of Marketing, Vol. 42 No. 1/2, pp. 35 -38

Finn, A. (2005), "Reassessing the foundations of customer delight", Journal of Service Research, Vol. 8 No. 2, pp. 103-116.

Iacobucci, D., Ostrom, A. (1993), "Gender differences in the impact of core and relational aspects of services on the evaluation of service encounters", Journal of Consumer Psychology, Vol. 2 No. 3, pp. 257-286. 
Iverson, K. (2000), "Managing for effective workforce diversity”., Cornell Hotel and Restaurant Administration Quarterly, Vol. 41 No. 2, pp. 31-39.

Keinningham, T.L.,Goddard, M., Vavra, T. \& Laci, A. (1999), “Customer delight and the bottom line", Marketing Management, Vol. 8, No. 3, pp. 57-64.

Kumar, A., Olshavsky, R., \& King, M. (2001), "Exploring the antecedents of customer delight”, Journal of Consumer Satisfaction, Dissatisfaction and Complaining Behavior, Vol. 14, pp. 14-27.

Magnini, V. , J. Crotts, \& A. Zehrer (2010), "Identifying drivers of customer delight through travel blog analysis”, Journal of Travel Research, Vol. 49, No. 2, pp. 153-164.

Markus, H. R., \& Kitayama, S. (1994), “The cultural construction of self and emotion: Implications for social behavior”, In S. Kitayama \& H. R. Markus (Eds.), Emotion and culture: Empirical studies of mutual influence. Washington, DC: American Psychological Association.

Meyers-Levy, J., Maheswaran, D. (1991), “Exploring differences in males' and females' processing strategies”, Journal of Consumer Research, Vol. 18 No. 1, pp. 63-70.

Meyers-Levy, J. (1991), “Gender differences in the use of message cues and judgments”, Journal of Marketing Research, Vol. 28 No. 1, pp. 84-96.

Oh, H., Parks, S., \& Demicco, F. (2002), “Age and gender-based market segmentation: A structural understanding”, International Journal of Hospitality and Tourism Administration, Vol. 3 No. 1, pp. 1-20.

Oliver, R. (1980), “A Cognitive model of the antecedents and consequences of satisfaction decisions:”. Journal of Marketing Research, Vol. 7 No.4, pp. 460-469. 
Patterson, K. (1997), “Delighted clients are loyal clients”, Rough Notes, Vol. 140 No. 3, pp. 221-234.

Rust, R.T., and R.L. Oliver. (2000), “Should we delight the customer?” Journal of the Academy of Marketing Science, Vol. 28,No. 1, pp. 86-94.

Schneider, B., and D. Bowen. (1999), "Understanding customer delight and outrage”, Sloan Management Review, Vol. 4, No. 1, pp. 35-46.

Sheth, J. N., Newman, B. I., \& Gross, B. L. (1991), “Consumption Values and Market Choices”. Cincinnati, OH: South-Western Publishing Co.

Skogland, I., and J. Siguaw. (2004), “Are your satisfied customers loyal?”, Cornell Hotel and Restaurant Administration Quarterly, Vol. 45, No. 3, pp. 221-234.

Torres, E. and S.F. Kline. (2006), "From customer satisfaction to delight: A model for the hotel industry", International Journal of Contemporary Hospitality Management. Vol. 18, No. 4, pp. 290-301.

Torres, E., Kline, S. (2013), "From customer satisfaction to customer delight: Creating a new standard of service for the hotel industry”. International Journal of Contemporary Hospitality Management, Vol. 25 No. 5

Wang, X. (2011), “The effect of unrelated supporting service quality on customer delight, satisfaction, and repurchase intentions", Journal of Service Research, Vol. 14 No. 2, pp. $149-163$. 